\title{
ÉTICA NOS NEGÓCIOS: O CASO DA AR CONSULTORIA LTDA.
}

\author{
BUSINESS ETHICS: THE CASE OF AR CONSULTORIA LTDA
}

\author{
Recebido em: 02/07/2013 Aprovado em: 28/08/2013 \\ Avaliado pelo sistema double blind review \\ Editora Científica: Manolita Correia Lima
}

\section{FERNANDO FANTONI BENCKE fernando.bencke@unoesc.edu.br UNIVERSIDADE DO OESTE DE SANTA CATARINA}

\author{
SYLVIA MARIA AZEVEDO ROESCH \\ PELAYO MUNHOZ OLEA \\ UNIVERSIDADE DE CAXIAS DO SUL
}

\section{RESUMO}

A AR Consultoria Ltda., dos sócios e irmãos Alfredo e Rodolfo, especializada na venda de produtos químicos e na prestação de serviços para agroindústrias, nasceu com base em uma oportunidade visualizada por Rodolfo, tornar-se fornecedor da empresa em que trabalhava. Funcionário de uma agroindústria da cidade de Chapecó/ SC possuía conhecimentos técnicos e uma ótima relação com seus colegas superiores e subordinados. Procurou a empresa na qual era funcionário e ofereceu produtos similares, mais eficientes e com preços menores aos praticados pelos fornecedores atuais, mas se deparou com algo que não tinha conhecimento: a corrupção. Surgira o primeiro desafio ético da AR Consultoria: o pagamento de um "extra por fora" para se tornar fornecedor. Alfredo, recém-formado em Administração, empolgado com a possibilidade e oportunidade de empreender, aos poucos conheceu as dificuldades em iniciar um negócio próprio, a alta carga tributária, falta de incentivos, falta de crédito no mercado e a oportunidade de "ganhar um pouco mais" vendendo sem nota fiscal. Essas e outras situações marcaram as dificuldades de início da abertura de mercado da AR Consultoria Ltda. O objetivo do caso é apresentar uma situação real, presente em alguns ramos e setores organizacionais e que exija do leitor uma tomada de decisão, uma postura ética diante dos desafios morais apresentados. Palavras-chave: ética; corrupção; tomada de decisão.

\section{ABSTRACT}

AR Consultoria Ltda.,owned by brothers and partners Alfredo and Rodolfo, specializes in selling chemical products and providing agribusiness services. It was born of an opportunity glimpsed by Rodolfo to become a supplier for the company where he used to work. As an agribusiness employee in Chapecó/SC, he had built up technical knowledge and an excellent relationship with his colleagues, at the upper and lower levels. He contacted his previous employer and offered similar products, but which were more efficient and cost less than the competition. However, he was confronted with a problem he had not faced before: corruption. The first ethical challenge faced by AR Consultoria was whether or not to pay a bribe in order to become a supplier. Alfredo, a recent BA graduate, was excited about the possibilities and opportunities of being an entrepreneur and gradually learned the difficulties involved in starting up one's own business: the significant taxes, lack of incentives and credit available and the opportunity to "make a little extra" through informal sales. AR Consultoria's entry to the market was marked by these and other difficulties. This case aims at presenting a real situation that can be found in some organizational sectors areas, which demands readers to take a decision and an ethical stance when faced with moral challenges.

Keywords: ethics; corruption; decision making. 


\section{INTRODUÇÃO}

A empresa AR Consultoria Ltda., especializada na prestação de serviços e venda de produtos químicos para agroindústrias, tinha como sócios os irmãos Rodolfo, engenheiro químico, e o recém-formado em Administração Alfredo. Os irmãos constituíram a empresa na cidade de Chapecó-SC diante das oportunidades surgidas na agroindústria em que Rodolfo trabalhava. Parecia ser a grande oportunidade de realizar o sonho de ter o próprio negócio, quando ambos se deparam com situações de corrupção: pagar, subornar o comprador para inserir os produtos da AR Consultoria Ltda. no rol dos fornecedores e fechar uma negociação sob a condição de não emitir a Nota Fiscal e, assim, sonegar impostos, são as situações que marcam o presente caso e que exigem do leitor um tomada de decisão, uma postura ética diante dos desafios morais apresentados. Cair na tentação das emoções e aceitar as oportunidades de corromper ou seguir os valores éticos e morais, presentes, até então, na vida de Rodolfo e Alfredo? Qual é a conduta "correta"? Como agir?

\section{HISTÓRICO}

Rodolfo, engenheiro químico, tinha 35 anos e trabalhava desde 1995 em uma agroindústria. Iniciou como estagiário, sempre prezou por um bom relacionamento com os superiores, colegas e fornecedores, e logo assumiu uma posição privilegiada pelos serviços prestados à empresa. Era muito dedicado em sua função, trabalhava com afinco, "vestia a camisa da empresa", trabalhando, inclusive, depois do expediente e nos finais de semana, quando necessário. Acreditava nos valores expressos pela empresa: qualidade de vida, ética, confiança, sustentabilidade, integridade, comunicação e simplicidade. Ao iniciar na empresa, Rodolfo recebeu um treinamento sobre as normas, regras, condutas esperadas e procedimentos, as quais sempre tomou como base em suas decisões.

Alfredo, irmão mais novo de Rodolfo, com 22 anos de idade estava concluindo a graduação em Administração. Passou por experiências como estagiário em empresas prestadoras de serviços na área administrativa e 
tinha um grande sonho, como o de muitos recém-formados, em empreender num novo negócio e ser "dono do próprio nariz".

Rodolfo, um pouco cansado de exercer a mesma função, a última na qual foi incumbido como supervisor de qualidade por quase cinco anos, pensou em abrir uma empresa na área de consultoria, assessoria e revenda de produtos químicos para agroindústrias. Assim como qualquer pessoa bem empregada, tinha o receio de deixar um bom salário, que possibilitava tranquilidade, por algo incerto e imprevisível. Tal receio durou seis meses até que uma oportunidade em especial chamou a sua atenção. Por conhecer todo o processo, produtos utilizados e fornecedores, começou a pesquisar empresas de outros estados que poderiam oferecer melhores produtos com preços mais atraentes. Logo se empolgou por conhecer novas tecnologias que possibilitavam uma redução de custos aos potenciais clientes. Rodolfo não pensou duas vezes, abrir uma empresa que poderia prestar serviços para a atual agroindústria que trabalhava e estender às demais da região.

Porém, Rodolfo precisava de auxílio e de uma parceria para contribuir com o seu novo negócio e chamou seu irmão Alfredo para uma conversa: - Rodolfo: Alfredo, esses anos de experiência na empresa mostraram algumas oportunidades; estou a fim de ousar e entrar no mercado. Estou pensando em abrir uma empresa de consultoria e revenda de produtos na área de aditivos químicos. O que você acha?

— Alfredo: Acho ótimo!

- Rodolfo: Sabe Alfredo, estou um pouco desmotivado, pois já assumi as funções que gostaria e sinto que ficarei um bom tempo no atual cargo, função que ocupo já há cinco anos. Tenho um bom relacionamento, conheço todo o processo e tenho ideias que podem contribuir com a empresa, como fornecedor, mas tenho pouco conhecimento na área administrativa e de gestão. Então, pensei em convidá-lo para ser sócio. Serei responsável com a parte de consultoria, atendimento técnico e vendas e você por toda a parte administrativa.

Alfredo se sentiu orgulhoso pelo convite de seu irmão e, de pronto, aceitou. Rescindiu seu contrato de estágio na empresa em que trabalhava e começou a pesquisar sobre os procedimentos legais de abertura da empresa, 
um barracão para alugar e os custos para instalação da nova empresa, a AR Consultoria Ltda.

\section{PRIMEIRAS DIFICULDADES}

Alfredo motivado com o desafio começou a pesquisar sobre os passos para a abertura de uma empresa. Procurou um escritório de contabilidade e surpreendeu-se com as altas taxas de encargos e tributos praticados no Brasil e a burocracia quanto aos documentos e procedimentos necessários. Alfredo começou a fazer um planejamento sobre o investimento, projetou os gastos e estimou o lucro e rentabilidade necessários à sobrevivência da empresa, chegando ao valor de R\$4.000,00 mensais de despesas fixas para o primeiro ano.

Então, Alfredo alugou um pequeno barracão em um bairro próximo e logo encontrou as primeiras dificuldades com o comércio local, como a falta de créditos dos fornecedores de equipamentos de escritórios e demais equipamentos necessários à instalação da AR Consultoria Ltda. Por ser uma empresa nova, alguns locais, inclusive, não aceitavam cheque e não parcelavam as vendas, exigindo dos sócios um capital de giro ainda maior do que pensaram para iniciar as atividades.

\section{SERVIÇOS PRESTADOS PELA AR CONSULTORIA LTDA.}

A AR Consultoria Ltda. prezou por oferecer um processo de profissionalização na prestação de serviços, que consiste em identificar e priorizar as necessidades do cliente, traduzindo-as em oportunidades de melhoria na qualidade, produtividade e rentabilidade. Ao contrário de seus concorrentes, que apenas vendiam os produtos solicitados pelas indústrias, a empresa oferecia acompanhamento técnico e a instalação de bombas dosadoras responsáveis por dosar os produtos de forma automática, evitando desperdícios, diminuindo a necessidade de mão de obra, aumentando a qualidade no processo. Ao oferecer um produto, a AR Consultoria Ltda. propunha realizar os testes necessários para a viabilidade de instalação das bombas dosadoras.

O processo de profissionalização na prestação de serviços adotado pela AR 
Consultoria, cujo foco é atender as necessidades e exigências do cliente, é: 1 Confiabilidade técnica;

2 Comprometimento em ajudar o cliente para resolver os problemas;

3 Confiabilidade no sistema de aplicação de produtos;

4 Monitoramento dos resultados (Acompanhamento técnico contínuo); e 5 Preço.

\section{AS NEGOCIAÇÕES}

Rodolfo começou a formalizar as parceiras com fornecedores e clientes. Realizou uma viagem a São Paulo para conhecer o seu principal fornecedor $\mathrm{e}$, posteriormente, visitou feiras nacionais que tratavam sobre a área de seu novo negócio. Estava cheio de novidades sobre o setor e produtos a serem oferecidos.

Aos poucos, a AR Consultoria sentiu a dificuldade de inserir seus produtos no processo de cotação de algumas indústrias devido à falta de interesse de funcionários do setor de compras e pelo desconhecimento dos preços praticados pelos fornecedores, pois as indústrias não forneciam os preços praticados pelos seus fornecedores ao mercado, dificultando, assim, a formalização de uma política de preços adequada. Em outras, a AR Consultoria participou de verdadeiros "pregões", em que as agroindústrias estabeleciam um preço mínimo, tornando-o público, e deixavam a livre mercado para receber propostas de diversos fornecedores. Os sócios conheceram, então, a realidade das empresas inseridas neste tipo de negócio. O "jogo de cintura", ou seja, a flexibilidade e a criatividade se apresentaram tão importante quanto o conhecimento técnico, os melhores preços, serviços, produtos e atendimento.

A agroindústria em que Rodolfo trabalhava foi a primeira a ser procurada. Primeiramente, Rodolfo entrou em contato com departamento técnico, apresentou os serviços disponibilizados e realizou os testes para identificar o melhor tratamento tecnológico disponível. Depois de todo o trabalho realizado, testes aprovados em laboratórios, atendendo o padrão exigido, equipamentos analisados e a escolha da melhor metodologia a ser aplicada, Rodolfo sugeriu uma inovação tecnológica que resulta na alta eficiência no 
processo de dosagem na mistura dos produtos: um sistema automatizado que poderia reduzir em até $30 \%$ os custos. Até então, o processo era realizado manualmente por um funcionário, o que poderia gerar incertezas e inexatidão da quantidade adequada do produto a ser utilizado. Enfim, Rodolfo tinha todos os requisitos para se tornar fornecedor e foi chamado pelo Sr. Francisco do departamento de compras da Agroindústria.

\section{RODOLFO E O COMPRADOR DA AGROINDÚSTRIA EM QUE TRABALHAVA}

- Francisco: Olá Rodolfo, tudo bem? Recebi seu rol de produtos e o resultado dos testes realizados e creio que podemos fazer uma boa parceria. - Rodolfo: Isso mesmo, Sr. Francisco, atuei por nove anos nesta empresa e conheço muito bem o processo produtivo. Tenho o produto certo e garanto que resultará na diminuição de custos em até 30\%.

- Francisco: Fale-me mais sobre o seu produto e sua oferta.

- Rodolfo: Sei que o aditivo químico que vocês utilizam hoje custa $\mathrm{R} \$ 60,00$ o litro. O produto que lhe ofereço custará $\mathrm{R} \$ 42,00$ o litro, ou seja, $30 \%$ a menos que o atual.

— Francisco: Interessante Rodolfo! E o que eu poderia ganhar com esta vantagem?

— Rodolfo: Realmente Francisco, como vocês utilizam I.ooo litros/mês, pode gerar uma diferença de $\mathrm{R} \$ \mathrm{I} 8.000,00$ mensais à empresa, um recurso significativo que a empresa poderia investir em outros processos. Ao total de I2 meses, que é o contrato que lhe proponho, pode gerar uma economia de $\mathrm{R} \$ 216.000,00$. Sem contar que vocês poderão readequar o funcionário que dosa manualmente o atual produto para outro setor.

- Francisco: Rodolfo, acho que não entendeu, para poder inserir o seu produto, terei que lhe cobrar uma "comissão", entende, um "extra por fora" que pode garantir um contrato de I2 meses de exclusividade de compra de I.ooo litros mensais como propõe. Faço-lhe uma contraproposta, inserimos seu produto por R\$44,00 o litro e você me paga por fora $\mathrm{R} \$ 2,00$ o litro. O pagamento deve ser feito em dinheiro em um ambiente fora daqui. O que acha? Os fornecedores pelo qual sou responsável trabalham assim e é a única forma de inserir o seu produto. 
- Rodolfo, assustado e sem saber o que dizer, respondeu: Entendi, Francisco, irei conversar com meu sócio e darei um retorno.

Rodolfo voltou para casa estarrecido com a conversa que teve e disposto a decidir com Alfredo o caminho e a decisão a serem tomados.

\section{ALFREDO E O PRIMEIRO POSSÍVEL CLIENTE}

Embora Alfredo tivesse ficado responsável pela parte administrativa, dedicou um tempo para conhecer um pouco sobre os produtos oferecidos pela AR Consultoria Ltda. Começou a fazer ligações para potenciais clientes, apresentando sua empresa e oferecendo o rol de produtos disponíveis. Após algumas ligações, recebeu o retorno de Manuel, gerente de uma indústria, que conhecia Rodolfo e necessitava de roo $\mathrm{kg}$ de aditivo para ração animal em caráter de urgência.

- Manuel: Alô, é da AR Consultoria Ltda?

- Alfredo: Sim, como posso ajudar?

- Manuel: Aqui é o Manuel, da Máximus Indústria. Recebi seu catálogo de produtos e gostaria de cotar too kg de aditivo para ração animal; e se o produto for bom, posso comprar durante os próximos 06 meses, mas a primeira entrega deve ser realizada na próxima semana. Gostaria de uma cotação e de saber se tem condição de me atender.

Rodolfo em uma das viagens que fez conseguiu uma parceria com um fornecedor que conhecia e adquiriu justamente os $100 \mathrm{~kg}$ do produto solicitado, com prazo de pagamento para 45 dias. Ou seja, era a oportunidade da primeira venda da empresa.

- Alfredo: Manuel, posso lhe atender, sim, pois tenho o produto em estoque. O valor com frete para os Ioo $\mathrm{kg}$ fica $\mathrm{R} \$ 22.000,00 \mathrm{com}$ prazo de pagamento para 30 dias. Posso faturar? Preciso dos dados para cadastro e emissão da Nota Fiscal.

— Manuel: Ok, podemos negociar a questão da nota fiscal?

- Alfredo: pergunta: Como assim?

- Manuel: Alfredo, não tem a necessidade de emissão de nota fiscal do seu produto para a minha empresa neste momento. Faço-lhe uma contraproposta. Fechamos em R\$21.000,00 sem nota fiscal. Ok? 
- Alfredo: Desculpe Manuel, estamos iniciando agora no mercado. Preciso conversar com o meu sócio. Lhe retorno a seguir, abraços.

Alfredo, ao mesmo tempo em que está ansioso para dizer ao irmão e sócio que conseguira sua primeira venda, sente sua consciência pesar com a tomada de decisão que a empresa adotará. Os encargos e impostos da venda com nota fiscal chegam a aproximadamente $15 \%$ e a diferença em relação ao não pagamento dos tributos podem gerar um lucro ainda maior para empresa que está iniciando e que ainda não visualiza outras vendas.

\section{AS CHANCES E OS RISCOS}

Rodolfo ficou surpreso com a conversa que teve com Francisco, pois até então não sabia da "condição' estabelecida para entrar com seu produto, o que prejudicaria todo seu planejamento e desejo de empreender na AR Consultoria Ltda. Tinha as melhores condições técnicas e tecnológicas para atender o cliente, o melhor preço e melhores condições, mas desconhecia a "oportunidade" proposta. Rodolfo tem a chance de inserir o seu produto que pode render um lucro de $\mathrm{R} \$ 8.000,00$ mensais durante um ano, garantindo assim um pró-labore aos dois sócios e o pagamento de todas as despesas fixas mensais com a venda para apenas um cliente. Ou seja, seria a tranquilidade, em termos de caixa, necessários à empresa durante os próximos I2 meses, os mais difíceis para uma empresa se estabelecer. Mas, em contrapartida, deverá agir de forma desonesta com a empresa que lhe dera todas as oportunidades profissionais até agora, e pagar um "extra", ou seja, contribuir com a corrupção para inserir o seu produto. Além do mais, estaria agindo contra os seus valores morais e profissionais, princípios que o tornaram um profissional referência no que faz. Tinha em mente também a alta competitividade no ramo e temia que a empresa concorrente poderia aceitar as condições estabelecidas por Francisco.

Alfredo não sabia esconder a angústia e dúvidas sobre a sua primeira venda que poderia resultar no pagamento de todas as despesas fixas durante os próximos 06 meses. Vê a possibilidade de vender, podendo ganhar um pouco mais devido a não emissão da nota fiscal. Por um lado, o cliente não faz questão de comprar com nota fiscal e barganhou essa condição na 
negociação, e por outro, a AR Consultoria poderia ganhar um pouco mais, devido à alta taxa tributária, mas iniciar suas atividades de forma ilegal. Alfredo também se sente revoltado por conhecer a alta taxa tributária do país, por saber que muitas empresas concorrentes sonegam impostos e que o governo aplica indevidamente os recursos destinados à população, como lazer, saúde e educação. Sabia que, se não aceitasse a condição de seu possível cliente, ele procuraria outra empresa que poderia fornecer o produto conforme os interesses e condições estabelecidas. Apesar de possuir a consciência ética de que estaria agindo contra os princípios legais e morais, ficou em dúvida sobre qual decisão tomar. 


\section{NOTAS DE ENSINO}

\section{UTILIZAÇÃO RECOMENDADA}

A discussão sobre ética nos negócios pode ser utilizada em diversas disciplinas que consubstanciam os temas relacionados à gestão de serviços, estratégia empresarial, ética, empreendedorismo, plano de negócios etc., preferencialmente em cursos de graduação.

\section{OBJETIVOS DE APRENDIZAGEM}

O caso da AR Consultoria Ltda. apresenta uma realidade muitas vezes disfarçada, mas que, infelizmente, está presente no dia a dia de alguns ramos, setores ou organizações. Por meio da análise do caso, é possível abordar e refletir sobre alguns temas de aprendizagem, entre eles:

- Discutir os conceitos de moral e ética no mundo dos negócios;

- Identificar os fatores que podem ser considerados uma chance ou um risco para a prospecção da empresa e assim, influenciar na decisão;

- $\quad$ Exigir do leitor uma tomada de decisão, uma postura ética diante dos desafios morais apresentados;

- Discutir estratégias que podem ser adotadas pelas empresas para evitar a corrupção.

\section{QUESTÕES PARA DISCUSSÃO DO CASO EM SALA DE AULA}

1 Rodolfo deve escutar a sua consciência ética e não cair na tentação, ou deve aceitar o pagamento de um extra, garantindo assim as suas primeiras vendas e receitas da empresa? Como você agiria e por quê?

2 Como os sócios podem lidar com as oportunidades de sonegação surgidas na experiência de Alfredo? Devem respeitar as legislações federal, estadual e municipal sabendo das dificuldades em se manter no negócio ou podem se omitir, aceitando a venda sem nota fiscal, já que estão iniciando as atividades e a chance de sonegar é maior que o risco de serem descobertos naquele momento? O que você faria?

3 Qual(is) é(são) a(s) alternativa(s) de Rodolfo para inserir seus produtos 
no rol de fornecedores, evitando a corrupção?

4 Como as empresas podem evitar a corrupção interna? Quais ações poderiam adotar?

5 Em termos éticos, qual é a sua opinião sobre as diferentes formas de negociação utilizadas por algumas empresas? "[...] as indústrias não forneciam os preços praticados pelos seus fornecedores ao mercado, dificultando, assim, a formalização de uma política de preços adequada. Em outras situações, a AR Consultoria participou de verdadeiros "pregões", em que as empresas estabeleciam um preço minimo, tornando-o público e deixavam a livre mercado para receber propostas de diversos fornecedores" Qual forma apresentada é mais ética no seu ponto de vista?

6 Qual é a relação da ética com o lucro no mundo dos negócios? A ética pode gerar lucro, ou é uma inibidora do lucro no mundo atual? Qual é a sua opinião?

\section{ALTERNATIVAS PARA ANÁLISE DO CASO}

Para análise do caso, sugere-se uma leitura individual prévia do aluno anterior à aula. Em sala de aula, com aproximadamente 30 minutos, uma (re)leitura e análise individual do caso e resolução da questões apresentadas. Após a (re)leitura individual, formar grupos de até cinco alunos para discutir o caso e as respostas individuais. Em 30 minutos, os acadêmicos deverão chegar a um consenso, podendo utilizar materiais de apoio. Após, os grupos apresentam em plenária suas respostas em forma de discussão com os demais grupos, acompanhados pelos apontamentos do professor. Nesse momento, é exigido experiência e controle do professor sobre os argumentos dos alunos e a condução da aula. Por se tratar de um assunto polêmico e que exige o ponto de vista individual, o professor será responsável por apontar os caminhos necessários para compreensão do conteúdo exposto: ética nos negócios.

Para a análise do caso pelos alunos, se faz necessária uma apresentação anterior do professor, com auxilio de textos que auxiliem a compreensão acerca dos conceitos de ética, moral e valores. A condução da discussão deve ser realizada no sentido de exigir do aluno uma tomada de decisão, uma 
postura diante do caso apresentado, corromper ou não corromper e, nesse meio tempo, o professor deve indicar os caminhos adotados como corretos para empresas que desejam prosperar no mercado por meio de uma postura ética acima de qualquer obstáculo ou aparente benefício em curto prazo.

\section{CONCEITOS DE ÉTICA, MORAL E VALORES}

Para auxiliar na resolução das questões e na decisão a ser tomada por Rodolfo e Alfredo, apresentamos a seguir os conceitos de ética e moral. Salientamos que a ética tem um caráter individual e busca a tomada de decisão mais correta possível. Mas o que é correto? Assim nasce a discussão sobre o conceito de ética e moral.

A Ética, do grego ethikos, costume, comportamento, é a disciplina filosófica que busca refletir sobre os sistemas morais elaborados pelos homens, buscando compreender a fundamentação das normas e interdições próprias a cada sistema moral (COTRIM, 2000). A ética é tradicionalmente entendida como um estudo, uma reflexão sobre os costumes ou ações humanas. Um comportamento correto em ética, não seria nada mais do que um comportamento adequado aos costumes vigentes, e enquanto vigentes, isto é, enquanto estes costumes tivessem força para coagir moralmente, o que aqui quer dizer, socialmente (valls, 1994).

Alguns autores preferem mencionar o que a ética não é. Não pode ser definida como uma série de proibições, um sistema ideal de grande nobreza na teoria, mas inaproveitável na prática, pois muitas pessoas acreditam que a ética é inaplicável ao mundo real, pois imaginam que a ética seja um sistema de normas simples e breves (SINGER, 2002).

De acordo com o autor "ética é a ciência do comportamento moral dos homens em sociedade", "objetivo da ética é a moral” (NALINI, 2012, p.28). É ciência, pois possui suas leis, métodos e objetos próprios de um determinado ramo do conhecimento. Como ciência, a ética procura extrair dos fatos morais os princípios gerais a eles aplicáveis. A moral pode ser entendida como um conjunto de normas adquiridas pelo hábito da prática. A moral não é ciência, é um objeto da ética. Trata-se de um conjunto de regras próprias de uma determinada cultura. "A ética é uma disciplina normativa, não por criar 
normas, mas por descobri-las e elucidá-las. Se conteúdo mostra às pessoas os valores e princípios que devem nortear a sua existência" (NALINI, 20I2, p.30). Nesse sentido, a ética age perante a moral, aprimorando e desenvolvendo o sentido moral do comportamento influenciando a conduta humana.

A ética se depara com práticas morais em vigor e, partindo delas, procura determinar a essência da moral, sua origem, sua natureza, o principio que rege a mudança de diferentes sistemas morais. Pode ser entendida como uma ciência do comportamento moral dos homens em sociedade e se preocupa em estudar como o homem age na sociedade diante de diferentes desafios morais (VÁSQUEZ, 20I2, p. 67).

Um dos grandes objetivos da ética é estudar o comportamento humano no interior de uma sociedade a fim de estabelecer níveis ou princípios que garantam uma convivência pacífica, diz respeito aos princípios de condutas que norteiam um indivíduo ao bem comum, o respeito à reciprocidade, e a busca de uma vida digna para todos. A ética lida com o que é moralmente bom ou mal, certo ou errado. Nesse sentido, a ética é individual, é um estilo de vida, uma tomada de decisão, uma ação, uma postura, uma escolha diante dos valores expressos como certo ou errado, ou seja, a ética nasce da reflexão de como agir diante de diferentes desafios morais.

O conceito de moral em sentido bem amplo pode ser entendido como um conjunto de regras de conduta admitidas em determinada época ou por um grupo de homens (ARANHA, 1993). Nesse sentido, o homem moral é aquele que age bem ou mal na medida em que acata ou transgride as regras do grupo. A moral é um conjunto de normas que orientam o comportamento humano tendo como base os valores próprios a uma dada comunidade, ou seja, moral é um conjunto de regras válidas para todo mundo que determina a conduta em sociedade para não ferir o direito do outro e respeitar o bem COMUm (COTRIM, 2000).

O homem age no mundo de acordo com valores. As ações sobre o mundo não são indiferentes, não se equivalem, são hierarquizadas de acordo com as noções de bem e de justo que os homens compartilham em um determinado momento. Em outras palavras, o homem é um ser moral, um ser que avalia sua ação baseado em valores (COTRIM, 2000). 
No campo da ética profissional, o valor profissional deve acompanharse de um valor ético para que exista uma integral imagem de qualidade A competência técnica e científica sem uma conduta virtuosa tende a resultados irreversíveis que podem prejudicar a imagem e reputação, quer seja da organização e do profissional envolvido (SÁ, 2004, p.I44).

\section{ÉTICA NOS NEGÓCIOS}

Após o entendimento dos conceitos propostos pelos autores, o aluno deverá se posicionar em relação à postura ética a ser adotada pela empresa.

Ser ético, hoje, mais do que antes, não é uma opção. Para pessoas e organizações, é questão de sobrevivência (мATOs, 2008). "A boa empresa não é apenas aquela que apresenta lucro, mas a que também oferece um ambiente moralmente gratificante, em que as pessoas boas podem desenvolver seus conhecimentos especializados e também suas virtudes" (ARRUDA; WHITAKER; RAMOS, 200I, p.57).

Nesse contexto, a função principal da empresa, todavia, não é o lucro, mas oferecer bens e serviços. Se há empresa, é porque existe demanda: clientes com necessidades a serem satisfeitas. Por isso surge à empresa, e a qualidade em servir é a sua responsabilidade básica. O lucro é objetivo dos negócios que a empresa desenvolve para realizar sua missão de servir ao cliente. O lucro é exatamente isso, remuneração pelos serviços prestados. A Ética pode gerar lucro, pois a garantia de bom conceito se traduz em confiabilidade, fundamental para efetivar negócios.

Aética não está no discurso, mas no exemplo. A ética nos negócios é condicionada pela concepção e pelo comportamento ético na empresa, pela qualidade da cultura ambiente e do conceito público da organização. A obsessão por lucro acaba por gerar o não-lucro, pois desgasta parceiros e inibe clientes, processo pela qual dificilmente a Ética sai imune. Não é o lucro como tal, nem o seu valor, o que importa para a análise ética, e sim a maneira de obtê-lo, bem como a justa aplicação situacional do princípio do lucro (LEISINGER; SCHMIIT, 200I). 


\section{COMO EVITAR A CORRUPÇÃO}

O caso apresenta uma discussão sobre corrupção, colaboradores recebendo pessoalmente porcentagem ou "comissões". Nesse sentido, o aluno é exposto a um problema presente em muitas organizações, quando muitas vezes existe uma situação quase de extorsão, ou seja, a pessoa se vê forçada a ceder para poder permanecer no ramo.

Ética em vendas é tratada como uma atividade que implica uma poderosa força de persuasão, modelando atitudes e comportamentos. A influência do profissional de vendas pode extrapolar sua finalidade de informar, sugerir o consumo ou compra de um produto ou serviço e provocar reações diversas ao cliente. "O profissional de vendas deve se preocupar com a consistência de seus argumentos, evitando comover e chocar deliberadamente o consumidor com apelos que parecem ser suaves, corrompendo seus valores morais" (ARRUDA; WHITAKER; RAMO, 200I, p. 96). Uma organização preocupada com a ética deve selecionar o profissional que esteja convicto de que sua função consiste em um serviço e não uma mera operação de vendas.

A corrupção, nesse contexto, torna-se prejudicial para indivíduos envolvidos, não tem razão de ser para a respectiva empresa e é injusta com a sociedade atingida. Se não quisermos assistir passivamente a uma decadência dos costumes e nos tornar culpados de omissão, faz-se mister resistirmos ativamente. Uma boa maneira de começar esta resistência seria preservando das tentações os colaboradores que, no âmbito de seu trabalho, estejam expostos ao perigo da corrupção ativa ou passiva (LEISINGER; SCHMIIT, 200I). A prevenção começa onde os problemas da corrupção podem surgir, ou seja, nas próprias pessoas. Os autores estabelecem dez regras para evitar a corrupção e promover um ambiente ético nas organizações (LEISINGER; SCHмIIT, 200I, p. 84-85):

1 Dê bom exemplo. Evite tudo que possa levar seus colaboradores a concluir que as práticas de corrupção - mesmo ativas - são desejadas ou mesmo toleradas em sua empresa.

2 Obrigue por escrito seus colaboradores as normas ou códigos contendo proibições de corrupção ativa e passiva. Esclareça que as transgressões podem ter consequências empregatícias. 
3 Deixe claro se e até onde podem ser aceitos presentes, convites ou outras vantagens.

4 Exija dos colaboradores em posições estratégicas um esclarecimento sobre relações, financeiras ou outras, com fornecedores e clientes.

5 Realize com os colaboradores treinamentos sobre perigos de corrupção e sobre como reconhecê-la

6 Designe alguém na sua empresa com quem seus colaboradores possam obter aconselhamento sobre o alcance das proibições penais e da própria firma.

7 Designe em sua firma uma ou várias pessoas a quem observações referentes à corrupção possam ser diretamente denunciadas. Deixe claro que tais denúncias não terão nenhuma consequência negativa para o denunciante.

8 Introduza, na medida do possível, o "princípio dos quatro olhos" e, também quando necessário, a rotatividade. Exija documentação detalhada de tudo quanto ocorre.

9 Informe seus parceiros de negócios sobre as regras que vigoram em sua empresa e exija procedimentos correspondentes.

10 Reforce os controles internos por meio de um nível mais elevado de formação, de prestígio e de fiscalização. Em caso de dúvida, recorra a fiscais ou peritos de fora. Denuncie à polícia violações da lei e providencie apresentação de queixa.

\section{ALTERNATIVAS ESTRATÉGICAS DA EMPRESA}

É importante que o aluno compreenda que o papel da AR Consultoria Ltda. não é somente o lucro e que a empresa deve manter uma postura ética em seus negócios. Ao optar por pagar um "extra", uma "comissão", e vender sem nota fiscal, a empresa estará criando a sua identidade e imagem no mercado.

A venda pode ser facilitada pela criação de uma rede de relacionamento. Essa rede pode aumentar ou diminuir conforme as escolhas dos gestores da empresa. Uma estratégia que pode ser adotada é a profissionalização da prestação de serviços, identificar e priorizar as necessidades do cliente, 
traduzindo-as em oportunidades de melhoria na qualidade dos serviços prestados, agregando o maior número possível de soluções à empresa, incorporando ao preço do produto e/ou serviço.

\section{FONTE DE DADOS}

Os dados relatados neste caso tratam de uma situação real vivenciada pelo autor e por entrevistas concedidas pelo sócio majoritário, Rodolfo.

* Os nomes das empresas e dos sócios são fictícios para preservar as fontes do caso real. 


\section{REFERÊNCIAS}

ARRUDA, M.C.C. de; WHITAKER, M. do C.; RAMOS, J.M.R. Fundamentos de ética empresarial e econômica. São Paulo: Atlas, 2001.

COTRIM, G. Fundamentos da filosofia: história e grandes temas. 15.ed. São Paulo: Saraiva, 2000.

LEISINGER, K. M. Ética empresarial: responsabilidade global e gerenciamento moderno. 2.ed. Petrópolis/RJ: Vozes, 2002.

MOREIRA, J.M. A ética empresarial no Brasil. São Paulo: Pioneira, 2002.

NALINI, J.R. Ética geral e profissional. 9.ed. São Paulo: Revista dos Tribunais, 2012.

SÁ, A.L. de. Ética profissional. 5.ed. São Paulo: Atlas, 2004.

SÁNCHES VAZQUES, A. Ética. 32.ed. Rio de Janeiro: Civilização Brasileira, 2012.

SINGER, P. Ética prática. 3.ed. São Paulo: Martins Fontes, 2002.

VALLS, Á.L.M. O que é ética. 9.ed. São Paulo: Brasiliense, 1994. 


\section{DADOS DOS AUTORES}

FERNANDO FANTONI BENCKE` fernando.bencke@unoesc.edu.br Mestre em Educação pela Universidade de Passo Fundo Instituição de vinculação: Universidade do Oeste de Santa Catarina Chapecó/SC - Brasil

Áreas de interesse em pesquisa: Ética, Inovação e Sustentabilidade.

*Av. Nereu Ramos, 3777-D Seminário Chapecó/SC 89813-000

\section{SYLVIA MARIA AZEVEDO ROESCH sylviaroesch@gmail.com}

Ph.D. em Administração/Relações de Trabalho pela London School of Economics Instituição de vinculação: Universidade de Caxias do Sul Caxias do Sul/RS - Brasil

Áreas de interesse em pesquisa: Métodos de Ensino e de Pesquisa em Administração.

PELAYO MUNHOZ OLEA pelayo.olea@gmail.com

Doutor em Administração pela Universitat Politècnica de Catalunya Instituição de vinculação: Universidade de Caxias do Sul Caxias do Sul/RS - Brasil

Áreas de interesse em pesquisa: Inovação, Gestão Ambiental e Métodos de Pesquisa em Administração. 